\title{
ALINHAMENTO ESTRATÉGICO NAS CADEIAS DE SUPRIMENTO DA INDÚSTRIA AUTOMOBILÍSTICA BRASILEIRA
}

\author{
Ricardo S. Martins \\ martins@ cepead.face.ufmg.br \\ Universidade Federal de Minas Gerais - Belo Horizonte, MG/Brasil \\ Osmar V. Souza Filho \\ osmar.br@gmail.com \\ Universidade Federal de Minas Gerais - Belo Horizonte, MG/Brasil \\ Susana Carla Farias Pereira \\ susana.pereira@fgv.br \\ Fundação Getúlio Vargas - São Paulo, SP/Brasil
}

Recebido em 29/03/2011

Aprovado em 25/06/2012

Disponibilizado em 01/12/2012

Avaliado pelo sistema double blind review

Revista Eletrônica de Administração

Editor: Luís Felipe Nascimento

ISSN 1413-2311 (versão on-line)

Editada pela Escola de Administração da Universidade Federal do Rio Grande do Sul.

Periodicidade: Quadrimestral

Sistema requerido: Adobe Acrobat Reader.

\section{RESUMO}

O objetivo do estudo foi analisar o alinhamento nas estratégias de suprimento adotadas pelos elos nas cadeias de suprimentos da indústria automobilística no Brasil. O conceito de alinhamento seguido foi aquele proposto por Vachon et al. (2009), de que o alinhamento se relaciona com a intensidade dos gaps entre os requisitos de um cliente e a ênfase dada por um fornecedor de primeira camada nestes mesmos requisitos ao lidar com os fornecedores de segunda camada. A unidade de análise são empresas industriais localizadas no Brasil, fornecedores de primeira camada de montadoras de automóveis. A amostra de vinte e oito empresas foi selecionada por critério de acessibilidade, a partir de uma relação de empresas do setor disponibilizada pelo Sindipeças, o principal sindicato patronal da categoria. As unidades de observação foram os gestores da área de suprimentos dessas empresas. Os resultados apontam que a dependência de um fornecedor em relação a uma montadora específica reforça o alinhamento estratégico nesta cadeia de suprimentos, e que as montadoras europeias possuem uma base de fornecedores diretos que adotam estratégias de suprimentos mais alinhadas com as suas próprias, quando comparadas com as montadoras norteamericanas e respectivas bases de fornecedores. No entanto, as cadeias se desalinham quando 
Alinhamento estratégico nas cadeias de suprimento da indústria automobilística brasileira prevalece a adoção de práticas colaborativas nas relações entre montadoras e primeira camada de fornecedores.

Palavras-chave: Suprimento, alinhamento estratégico, indústria automobilística

\title{
STRATEGIC ALIGNMENT IN THE BRAZILIAN AUTOMOTIVE SUPPLY CHAIN
}

\begin{abstract}
This study evaluates the degree of strategic alignment in the supply strategies adopted by the Brazilian automotive supply chains. The concept of alignment followed was that proposed by Vachon et al. (2009), that alignment is related to the intensity of the gaps between the requirements of a client and an emphasis on first-tier supplier in these same requirements when dealing with suppliers second tier. The unit of analysis are companies located in Brazil, first-tier suppliers to automobile manufacturers. The sample of twenty-eight companies were selected by criteria of accessibility, provided by SINDIPEÇAS. The units of observation were their supply managers. The results pointed that, the stronger the bonds between the automaker and its suppliers are, higher is the degree of alignment in the adopted supply strategies. Furthermore, European automakers supply chains have higher levels of strategic alignment compared to North-American automakers ones. However, the supply chains characterized by lower levels of strategic alignment are the ones where collaborative practices prevail in the relations.
\end{abstract}

Keywords: Supply management, strategic alignment, automotive industry.

\section{ALINEAMIENTO ESTRATÉGICO EN CADENA DE SUMINISTRO INDUSTRIA AUTOMOTRIZ BRASILEÑA}

El objetivo de este estudio fue examinar el alineamiento de las estrategias adoptadas por relaciones de suministro en cadenas de suministro de la industria automotriz en Brasil. El concepto de alineación que siguió fue la propuesta por Vachon et al. (2009), que la alineación se refiere a la intensidad de las diferencias entre los requisitos del cliente y el énfasis dado por un proveedor de primer nivel de estos mismos requisitos cuando se trata de proveedores de segundo nivel. La unidad de análisis son las empresas ubicadas en Brasil, proveedores de primer nivel a los fabricantes de automóviles. La muestra de veintiocho empresas fueron seleccionadas por criterios de accesibilidad, de una lista de las empresas del sector proporcionada por Sindipeças, el sindicato patronal principal. Las unidades de observación fueron los gestores de estas empresas de la zona de suministro. Los resultados muestran que la dependencia de un único proveedor para un fabricante específico refuerza el alineamiento estratégico en esa cadena de suministro, y los fabricantes europeos tienen una base de proveedores directos que adoptan estrategias para la oferta más acorde con sus propios, en comparación con los fabricantes de automóviles de EE.UU. y sus bases de proveedores. Sin embargo, las cadenas de la desalineación cuando la adopción de las prácticas vigentes de colaboración en las relaciones entre los ensambladores y los proveedores de primer nivel.

Palabras clave: Fuente, alineamiento estratégico, la automoción

$$
\text { REAd I Porto Alegre - Edição } 73 \text { - N } 3 \text { - set/dez } 2012 \text { - p. 581-606 }
$$




\section{Introdução}

A indústria automobilística mundial passou por intensas transformações nas últimas décadas. Dentre elas, merece a disseminação de práticas inovadoras adotadas pelas montadoras japonesas para a gestão dos processos internos e da cadeia de suprimentos (WOMACK et al, 2007).

No Brasil, uma importante transformação do setor automobilístico foi o processo intenso e concentrado de internacionalização das empresas participantes (CARVALHO, 2005), o que provocou o aumento da competição, gerando uma corrida em busca da remodelação das plantas produtivas. Este processo também resultou em novas práticas de gestão dos processos internos e da cadeia de suprimentos (LIMA, 2004; BRONZO et al., 2005; CARVALHO, 2005), dentro de uma nova configuração para a cadeia automobilística brasileira, com a adoção de um modelo horizontalizado, baseado em processos modulares de produção.

O principal resultado dessas transformações foi a aproximação entre as montadoras e os fornecedores de primeira camada, desenvolvendo um novo tipo de relacionamento pautado por ações de compartilhamento de informações e de colaboração entre as empresas, adotando como perspectiva um projeto único da cadeia (MONCZKA et al., 2009).

Porém, avanços adicionais estão condicionados à ampliação dos arranjos colaborativos para além dos fornecedores de primeira camada (FORD et al , 2008). Afinal, num ambiente em que predomina a competição entre cadeias de suprimento (CHRISTOPHER, 2007), a sustentabilidade de cada uma delas é dependente da capacidade de cada elo em gerar vantagens competitivas duradouras.

Concomitantemente ao estreitamento dos relacionamentos, outro fenômeno verificado na indústria automobilística brasileira foi a aproximação geográfica entre alguns fornecedores de primeira camada e seus clientes. A localização física tornou-se, em alguns casos, um critério relevante para a seleção de fornecedores (CARVALHO, 2005), viabilizando práticas logísticas otimizadas como entregas just-in-time e coletas milk run (LIMA, 2004).

A literatura que aborda o tema cadeias de suprimento tem sinalizado para a existência de evidências que apontam para a necessidade de alinhamento das estratégias individuais de cada elo, de maneira a atingir altos níveis de eficácia da estratégia das cadeias de suprimento (CHOPRA e MEINDL, 2011; VAN DER VAART e VAN DONK, 2006; CHRISTOPHER, 2007; VACHON et al., 2009).

REAd I Porto Alegre - Edição 73 - Nº 3 - set/dez 2012 - p. 581-606 
Alinhamento estratégico nas cadeias de suprimento da indústria automobilística brasileira

Adotando como ponto de partida esses pressupostos de alinhamento estratégico, bem como aqueles relacionados ao aumento da competição e da consequente reconfiguração do setor automobilístico brasileiro, o presente artigo teve como objetivo analisar o alinhamento nas estratégias de suprimento adotadas pelos elos nas cadeias de suprimentos da indústria automobilística no Brasil. O conceito seguido foi aquele proposto por Vachon et al. (2009), cuja premissa central propõe que o alinhamento se relaciona com a intensidade dos gaps entre os requisitos de um cliente e a ênfase dada por um fornecedor de primeira camada nestes mesmos requisitos ao lidar com os fornecedores de segunda camada.

Como método de pesquisa, adotou-se a estratégia quantitativa e análise dos dados com técnicas de estatística descritiva. As unidades de análise escolhidas para o estudo são empresas industriais localizadas no Brasil, fornecedores de primeira camada de montadoras de automóveis. Uma amostra de vinte e oito empresas foi selecionada por critério de acessibilidade. As unidades de observação escolhidas foram os gestores da área de compras dessas empresas. Entrevistas in loco foram realizadas, e utilizou-se como instrumento de pesquisa um questionário estruturado. Para a análise do alinhamento das estratégias de suprimento, foram considerados dez critérios de desempenho relevantes para o setor automobilístico. O procedimento de pesquisa adotado foi dividido em duas etapas: na primeira, considerou-se a avaliação da importância dos critérios de desempenho nos processos de seleção e avaliação de fornecedores de segunda camada; na segunda etapa, considerou-se a avaliação da importância dos critérios sob a perspectiva de cada uma das três principais montadoras atendidas pela empresa.

Duas segmentações foram feitas na análise do alinhamento estratégico: comparativo do alinhamento estratégico quando há variação na região de origem das montadoras; e comparativo do alinhamento estratégico quando há variação na intensidade do vínculo entre a montadora de automóveis e seu fornecedor de primeira camada. A ocorrência de diferenças no alinhamento estratégico quando há variação no vínculo das montadoras com os seus fornecedores de primeira camada é esperada, com vínculo intensos proporcionando maior alinhamento entre estratégias de suprimento. Quanto à origem das montadoras, o grau de maturidade das cadeias de suprimento das montadoras analisadas é similar no caso brasileiro, não sendo possível previamente estabelecer qualquer tipo de expectativa de comportamento para o alinhamento estratégico.

Este estudo oferece contribuições tanto sob a perspectiva acadêmica quanto gerencial. Uma destas refere-se à análise dos relacionamentos estabelecidos nas camadas mais distantes de REAd I Porto Alegre - Edição 73 - Nº 3 - set/dez 2012 - p. 581-606 
uma cadeia de suprimentos, algo ainda pouco explorado em pesquisas empíricas. Outra importante contribuição gerencial é a identificação de práticas que apóiem a expansão do novo modelo de arranjos colaborativos implantado pelas montadoras de automóveis no Brasil. Além disto, o estudo permite que se compreenda a dinâmica adotada pelas empresas na gestão dos suprimentos e as implicações destas ações na capacidade competitiva, tanto das empresas envolvidas quanto da cadeia de suprimentos como um todo.

O artigo está organizado em quatro seções, além desta introdução. Na próxima seção, foi feita uma revisão de literatura relacionada ao conceito de alinhamento estratégico em cadeias de suprimento e seus desdobramentos na indústria automobilística. Na seção seguinte, foi detalhada a metodologia da pesquisa, bem como as características da amostra de empresas. Posteriormente, foram apresentados e discutidos os resultados, que deram suporte à conclusão do estudo, apresentada na última seção.

\section{O alinhamento estratégico como pressuposto da eficácia em cadeias de suprimentos}

O ambiente de acirrada concorrência verificado globalmente a partir dos anos 80 está incentivando a formação de cadeias de suprimento integradas como forma de competição (CHRISTOPHER, 2007; CHOI e WU, 2009). Na base desse fenômeno está a alteração do foco para o cliente, o que exige coordenação e gerenciamento dos relacionamentos entre os parceiros de negócios, em uma rede comprometida com a oferta de valor superior ao usuário final (VAN DER VAART e VAN DONK, 2006; CHRISTOPHER, 2007). Trata-se da coordenação da integração de processos de negócios e dos fluxos de produtos, serviços e informações, desde o usuário final até os fornecedores originais da cadeia, que agregam valor ao consumidor final (HALLDORSSON et al., 2007).

Fundamentalmente, este modelo de gestão de redes de negócios tem como pressuposto a necessidade de que cada elo contribua com sua capacidade de especialização em determinadas atividades e na oferta de determinados recursos. Segundo Chopra e Meindl (2011), as empresas líderes são as principais responsáveis pelo cumprimento do planejamento estratégico da cadeia, difundindo as ações sistêmicas e os objetivos comuns, sinalizando a estratégia de atuação, incentivando o comprometimento, a coordenação e a integração entre os demais membros.

REAd I Porto Alegre - Edição 73 - Nº 3 - set/dez 2012 - p. 581-606 
Alinhamento estratégico nas cadeias de suprimento da indústria automobilística brasileira

Tais assertivas são corroboradas por Halldorsson et al (2007), ao afirmarem que a gestão das cadeias de suprimento deve ser orientada por uma estratégia única de atuação, coincidente com as características dos produtos - funcionais ou inovadores. Produtos funcionais, cuja demanda é previsível e o ciclo de vida longo, apontam para cadeias de suprimentos enxutas, pautadas pela eficiência em seus processos. Já os produtos inovadores, caracterizados por demandas menos previsíveis e ciclos de vida mais curtos, sugerem a necessidade de cadeias de suprimento mais flexíveis no mix de produtos, nos volumes e no desempenho das entregas (VAN DE VAART e VAN DONK, 2006).

Assim, entram em cena conceitos como eficiência - capacidade de operar de maneira enxuta, com menor nível de consumo de recursos - ou responsividade - capacidade de responder de maneira ágil a movimentos de mercado, operando com desempenho superior em quesitos como velocidade, flexibilidade e confiabilidade (VACHON et al., 2009). Cadeias de suprimento dirigidas pelas necessidades do mercado devem ser formatadas e gerenciadas em uma estratégia única apoiada em algum ponto do espectro entre eficiência ou responsividade (CHOPRA e MEINDL, 2011; CHRISTOPHER, 2007). Tal estratégia única torna possível que se atinja o alinhamento estratégico da cadeia de suprimentos. Para Chopra e Meindl (2011), a expansão do escopo do alinhamento estratégico ao longo da rede é uma forma de aprimorar o desempenho competitivo de toda a cadeia de suprimento.

O alcance do alinhamento estratégico surge de maneira gradual (LEE, 2004). Para este autor, o processo inicia-se quando há o alinhamento de informações sobre previsão de demanda e planos de produção, intensifica-se quando há o alinhamento de identidades, ou seja, a definição do papel e responsabilidades de cada membro, e seu prosseguimento ocorre quando incentivos são alinhados entre os elos para que a maximização dos retornos propicie aumento do desempenho da cadeia de suprimentos.

Diversos estudos mostram que a competição baseada no tempo estabelecida na indústria automobilística levou as montadoras de automóveis a estabelecerem vínculos colaborativos com seus fornecedores diretos (DYER e CHU, 2000; ZIRPOLI e CAPUTO, 2002; LIKER e CHOI, 2004; CHOI e WU, 2009). Um exemplo é a implantação de cinturões ou parques de fornecedores, cuja proximidade geográfica com as montadoras de automóveis facilita a sincronização dos processos logísticos de ambos e a redução dos custos decorrentes destes processos (PFOHL e GAREIS, 2005).

Além propriamente do trabalho seminal de Womack et al (2007), os trabalhos de corte longitudinal conduzido por Dyer $(1997 ; 1998)$, comparando as práticas de gestão de diferentes 


\section{Ricardo S. Martins, Osmar V. Souza Filho \& Susana Carla Farias Pereira}

montadoras em diferentes economias de mercado, nos anos 1990, destacaram a importância do alinhamento de estratégias e de processos de negócios em diferentes níveis das cadeias de suprimento dessa indústria.

No entanto, há um conflito potencial que deve ser mediado pela empresa focal da cadeia de suprimento. As empresas podem colocar seus próprios interesses acima dos interesses e objetivos da cadeia de suprimento como um todo, afetando negativamente o desempenho geral do conjunto (NARAYANAN e RAMAN, 2004). A ausência de alinhamento entre as estratégias individuais nesse conjunto de empresas levará a um baixo grau de coordenação entre as atividades desempenhadas e no compartilhamento de recursos (GADDE E JONSSON, 2007). Isso gera consequências no desempenho global da cadeia, tais como aumento nos custos totais, formação de estoques excessivos, queda de índices de flexibilidade produtiva, eficiência nos processos logísticos e um compartilhamento insuficiente de informações. Além disso, afeta o desenvolvimento das competências, a produtividade e a capacidade de inovação dessa cadeia de suprimento.

\subsection{A abordagem da Network Theory}

Uma cadeia de suprimentos é reconhecida como uma rede formada por clientes e fornecedores (CHOI e WU, 2009). Vachon et al. (2009) afirmam que o alcance do alinhamento estratégico nesta rede dependerá da interação entre empresas e fornecedores e clientes, e o alinhamento pode ser medido pela diferença entre requisitos dos clientes e a ênfase dada pela empresa nestes mesmos requisitos ao lidar com fornecedores.

Essa visão é compartilhada pela abordagem da Network Theory, que afirma terem as empresas pouca autonomia para agir de forma independente, ou seja, suas ações são influenciadas pelas atitudes e ações dos demais atores com os quais elas se relacionam (FORD et al., 2008). Na opinião destes autores, a posição de uma empresa é baseada em seu conjunto total de relacionamentos, e seu desenvolvimento se dará por meio da interação com esse grupo de empresas.

Gadde e Jonsson (2007) apontam como enunciado fundamental para a Network Theory o fato de que empresas individuais necessitam de recursos controlados e de atividades desempenhadas por outras empresas, e que a interação entre elas é a forma de acesso a esses recursos e atividades. A eficácia das cadeias de suprimento está relacionada com a capacidade 
Alinhamento estratégico nas cadeias de suprimento da indústria automobilística brasileira dos elos em combinar suas estruturas de recursos e estabelecer ligações entre as atividades desempenhadas internamente com aquelas desempenhadas pelos membros com os quais se relacionam (GADDE e HAKANSSON, 2001; GADDE E JONSSON, 2007).

Na opinião de Ford et al (2008), relacionamentos são o resultado de um processo de interação, em que conexões entre dois parceiros são desenvolvidas para produzir uma orientação mútua e comprometimento. Produzem algo que nenhum dos dois parceiros envolvidos obteria atuando de forma isolada e um status que não pode ser facilmente duplicado. Porém, segundo esses autores, é limitado o número de relacionamentos capazes de provocar um efeito significativo no desempenho das empresas.

Assim, para que as interações surtam efeito no desempenho de toda a rede, é evidente a necessidade de uma coordenação, capaz de capitalizar os efeitos da interação sob a forma de valor ao consumidor. Tal coordenação pode surgir sob a forma de ligações entre as atividades, atingidas por meio de adaptações - ajustes mútuos efetuados nas atividades, produtos, sistemas administrativos e processos de produção - que visam aprimorar a exploração dos recursos no âmbito da rede (GADDE E JONSSON, 2007). Nesse sentido, há coincidência entre a abordagem da Network Theory e a proposta de HALLDORSSON et al. (2007), ao afirmarem que a gestão das cadeias de suprimento envolve a coordenação de processos de negócios, em busca da maximização do valor perante o usuário final.

Pode se resumir a abordagem da Network Theory sobre relacionamentos entre empresas e seu impacto na formação de uma cadeia de suprimentos eficaz da seguinte maneira: um relacionamento se desenvolve entre duas empresas à medida que se coordenam algumas atividades desempenhadas por elas, combinações entre os recursos são estabelecidas e vínculos entre esses dois atores são formados; o valor da rede de relacionamentos resultante da interação entre os atores em uma network dependerá de como cada uma dessas camadas atores, atividades e recursos - será gerenciada pelas empresas (HALLDORSSON, 2007; FORD et al., 2003; GADDE E JONSSON, 2007; FORD et al., 2008).

Portanto, a colaboração entre as empresas é um pilar dos processos de coordenação de atividades inter-organizacionais. Sem projetos colaborativos, a capacidade de inovação e de desenvolvimento de competências entre parceiros estratégicos fica restrita à habilidade que cada empresa individual possua para este desenvolvimento. Perde-se a oportunidade de se alavancar a geração e a combinação de novos recursos no âmbito da díade, fortalecendo a capacidade competitiva de toda a cadeia de suprimento. 


\section{Ricardo S. Martins, Osmar V. Souza Filho \& Susana Carla Farias Pereira}

\section{Metodologia da pesquisa}

Este é um estudo empírico de caráter exploratório, que visa avaliar o grau de alinhamento estratégico entre montadoras de automóveis e seus fornecedores de primeira camada nas respectivas estratégias de suprimento.

A unidade de análise são empresas industriais localizadas no Brasil, fornecedores de primeira camada de montadoras de automóveis. As montadoras de automóveis não fazem parte da unidade de análise, uma vez que o modelo proposto de análise do alinhamento estratégico prevê uma comparação entre as práticas dos gestores de compras nos relacionamentos com a segunda camada e a percepção destes gestores quanto aos requisitos das montadoras nos relacionamentos com as empresas analisadas. A amostra de vinte e oito empresas foi selecionada por critério de acessibilidade, a partir de uma relação de empresas do setor disponibilizada pelo SINDIPEÇAS, o principal sindicato patronal da categoria. As unidades de observação foram os gestores da área de compras dessas empresas.

A estratégia de pesquisa adotada foi a realização de entrevistas in loco, usando como instrumento de pesquisa um questionário estruturado, contemplando as seguintes categorias de perguntas: a) caracterização da empresa; b) identificação das três principais montadoras atendidas; c) identificação dos três materiais mais relevantes adquiridos; d) avaliação da importância dos critérios de desempenho na seleção e avaliação de fornecedores de segunda camada; e) avaliação da importância dos mesmos critérios de desempenho, adotando-se o ponto de vista de cada uma das três principais montadoras atendidas, ao se relacionar com a empresa em estudo.

Os contatos com as empresas foram iniciados no mês de abril de 2009 e se estenderam até o mês de maio de 2010, sempre direcionados para o setor de suprimentos e logística. Todas as entrevistas foram feitas in loco, com o deslocamento do pesquisador para a sede da mesma, em data e horário agendados com o entrevistado, sendo um entrevistado por empresa da amostra, em um total de 28 questionários.

Para a análise do alinhamento das estratégias de suprimento, foram considerados dez critérios de desempenho relevantes para o setor automobilístico, identificados em levantamento bibliográfico realizado nos trabalhos de Hines (1995), Dyer e Chu (2000), Lima (2004) e Ogden (2006). Os dez critérios identificados são: suporte a projetos de novos produtos, pontualidade, rapidez no tempo de ciclo, preço, capacidade de produção, qualidade, 
Alinhamento estratégico nas cadeias de suprimento da indústria automobilística brasileira compartilhamento de informações sobre planos de produção, abertura de planilhas de custos, flexibilidade e estrutura financeira.

$\mathrm{O}$ procedimento de pesquisa adotado foi dividido em duas etapas. Na primeira, os respondentes foram solicitados a ordenar os dez critérios de desempenho de maneira decrescente, considerando a importância dos mesmos em processos de seleção e avaliação de fornecedores de segunda camada, sendo a nota 10 para o critério mais importante e a nota 1 para o menos importante.

$\mathrm{Na}$ segunda etapa, solicitou-se aos mesmos respondentes que adotassem o mesmo procedimento de atribuição da importância dos dez critérios de desempenho, desta vez sob a perspectiva de cada uma das três principais montadoras atendidas pela empresa. A intenção deste procedimento foi captar a percepção dos gestores de compras quanto aos requisitos dessas montadoras, a fim de avaliar como tais requisitos influenciam as práticas adotadas por estes gestores nos relacionamentos com os fornecedores de segunda camada das montadoras.

O método de análise do alinhamento estratégico utiliza como insumo as notas atribuídas pelos respondentes nestas duas etapas descritas. O alinhamento estratégico para cada par montadora-fornecedor é obtido pela soma das diferenças absolutas entre a importância de cada critério para a avaliação de fornecedores de segunda camada e a importância desses mesmos critérios para as montadoras nas relações com os fornecedores de primeira camada. Em outras palavras, o que alinhamento pode ser expresso como a diferença entre "quais práticas nossa empresa adota nos relacionamentos com os fornecedores" versus "quais práticas nossos clientes avaliam como sendo importantes nos relacionamentos conosco".

Quanto menor o número obtido para o alinhamento, mais alinhada é a estratégia de suprimentos do fornecedor de primeira camada com a estratégia da montadora. A fórmula para o cálculo é:

$$
A_{y}=\sum_{n=1}^{10}|C D F-C D C|
$$

Sendo:

$A_{y} \quad$ alinhamento estratégico para o par montadora-fornecedor $y$;

$n \quad$ critério de desempenho;

$C D F$ importância do critério de desempenho nas relações com o fornecedor de segunda camada;

CDC importância do critério de desempenho na perspectiva do cliente nas relações com o fornecedor de primeira camada;

REAd I Porto Alegre - Edição 73 - N 3 - set/dez 2012 - p. 581-606 
O alinhamento estratégico foi avaliado a partir da soma do alinhamento individual calculado para cada par montadora-fornecedor, obtido pela fórmula apresentada em (a). A figura 1 apresenta o modelo analítico do estudo sobre o alinhamento estratégico.

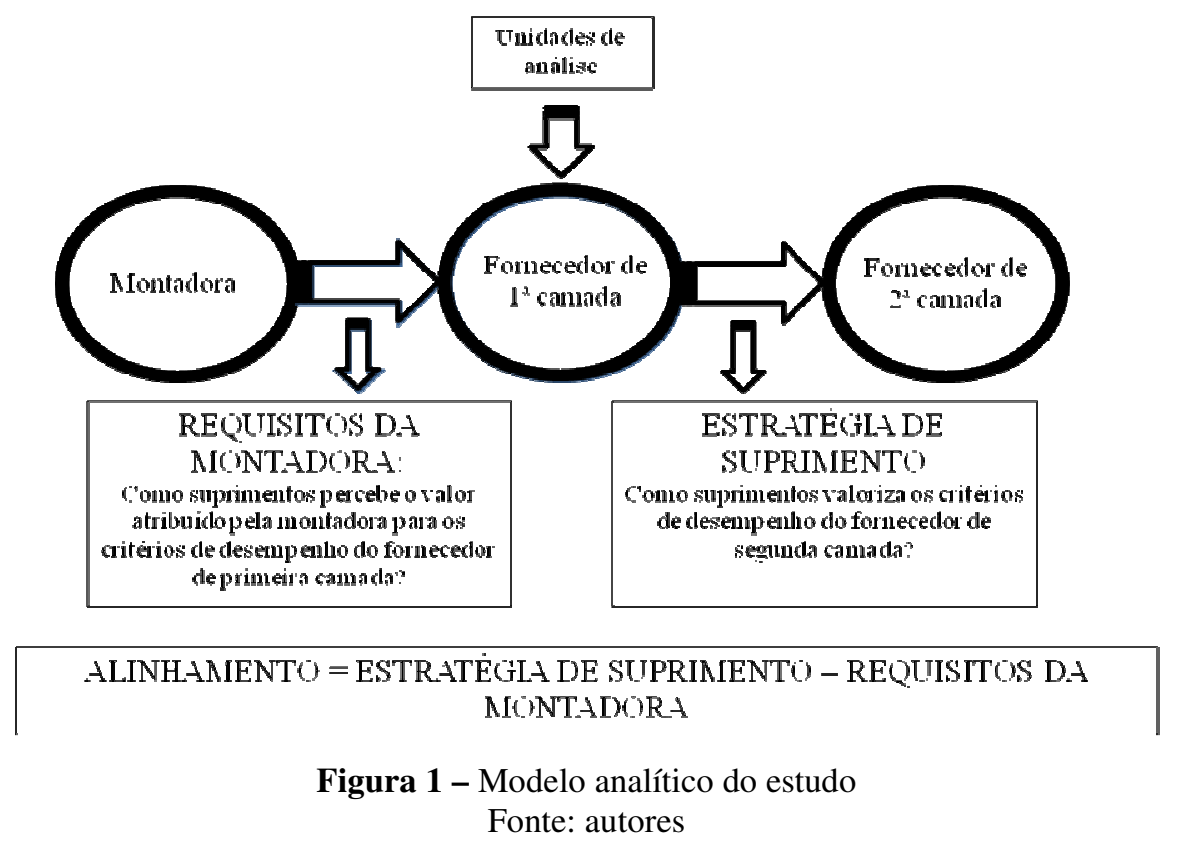

Foram feitas duas segmentações na análise do alinhamento estratégico. A primeira segmentação compara o alinhamento estratégico quando há variação na região de origem das montadoras. Foram consideradas apenas duas origens: a) Montadoras Européias, representadas pelas montadoras Fiat, Volkswagen, Renault, PSA Peugeot/Citroen, MercedezBenz e Iveco; e b) Montadoras Norte-Americanas, representadas pelas montadoras General Motors e Ford. As demais montadoras dessas duas origens não foram citadas como sendo um dos três principais clientes das empresas estudadas.

Montadoras de origens Japonesa ou Coreana - Toyota, Honda, Nissan, Mitsubishi, Hyundai e Komatsu, dentre outras - praticamente não foram citadas como sendo um dos três principais clientes das empresas amostradas, sendo, portanto, desconsideradas da análise. Isso ocorre em função da menor participação de mercado no Brasil, comparativamente aos outros dois grupos.

A Figura 2 apresenta o modelo analítico para este comparativo. 
Alinhamento estratégico nas cadeias de suprimento da indústria automobilística brasileira

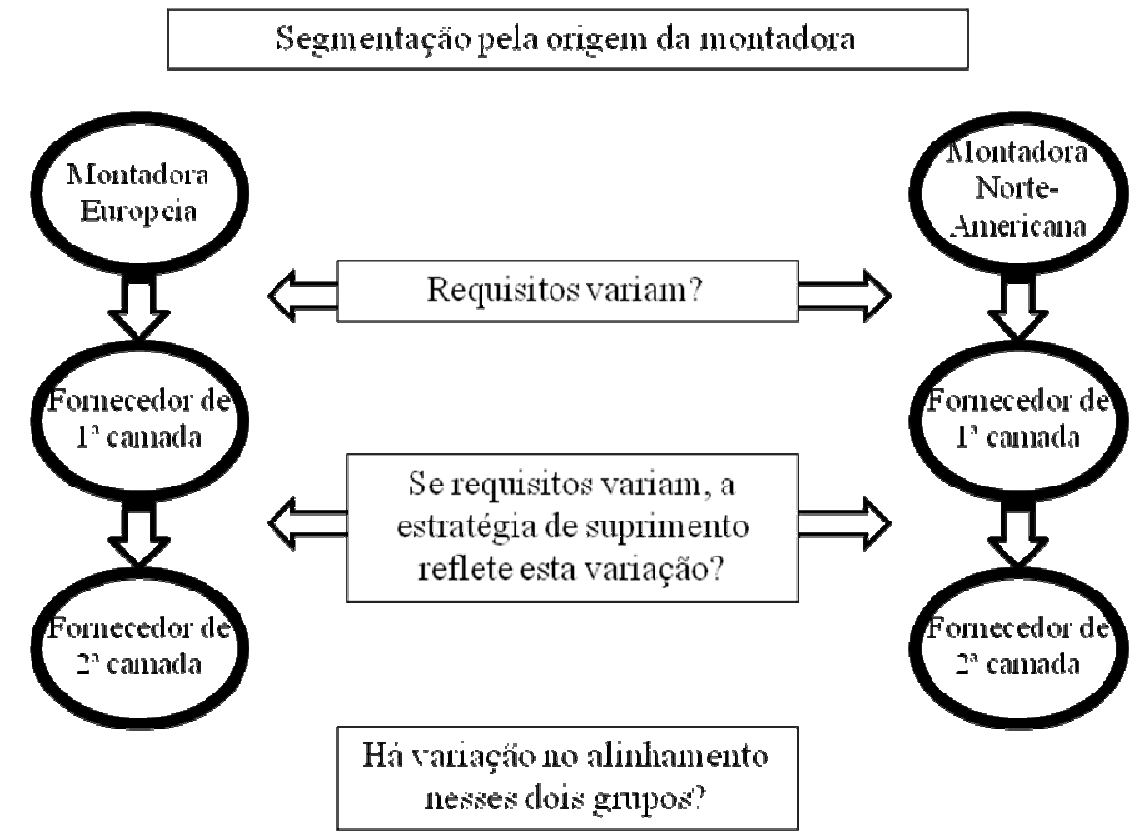

Figura 2 - Modelo analítico para o comparativo do alinhamento estratégico nas situações em que há variação na origem das montadoras

Fonte: autores

A segunda segmentação compara o alinhamento estratégico quando há variação na intensidade do vínculo entre a montadora de automóveis e seu fornecedor de primeira camada. As empresas foram divididas em dois grupos: a) Ocorrência de forte intensidade no vínculo, quando a montadora representa $50 \%$ ou mais do faturamento do fornecedor de primeira camada; e b) Ocorrência de vínculo disperso, quando a montadora representa menos do que $50 \%$ do faturamento do fornecedor de primeira camada.

A Figura 3 apresenta o modelo analítico para esta segunda segmentação.

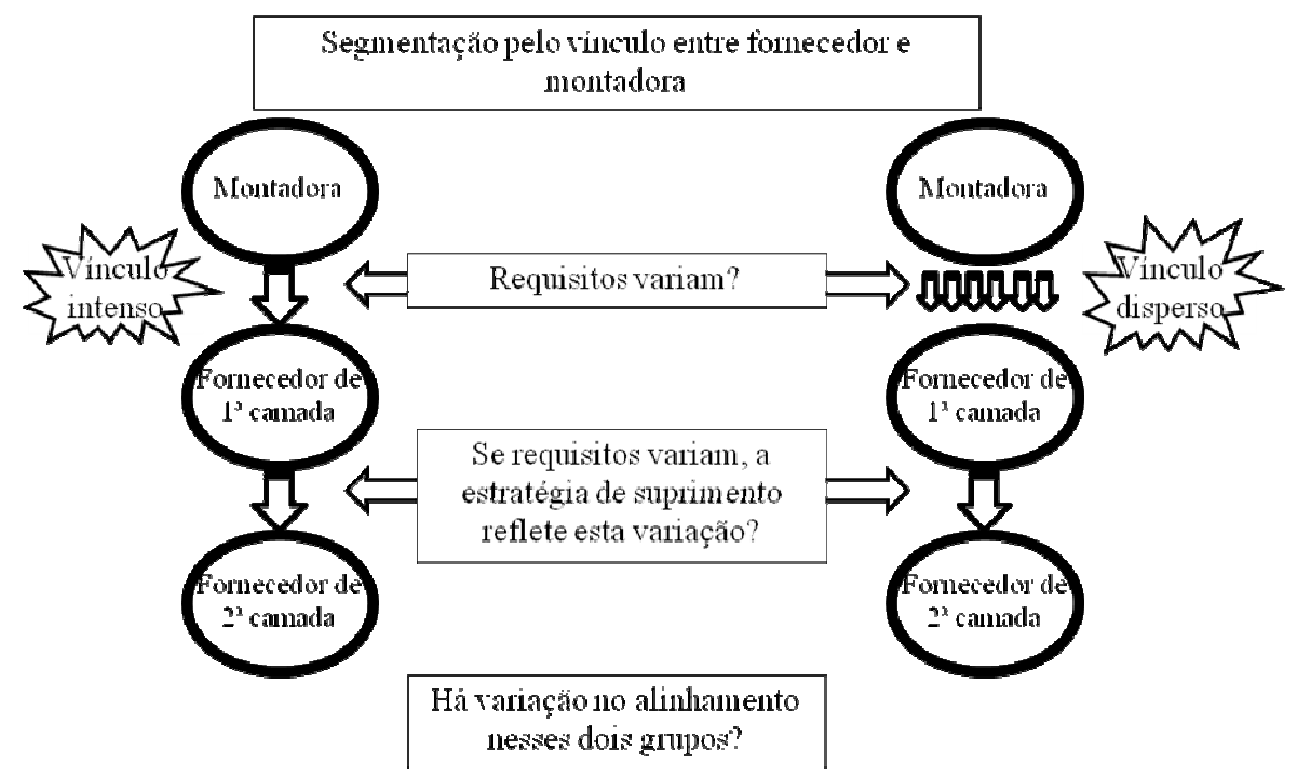

Figura 3 - Modelo analítico para o comparativo do alinhamento estratégico nas situações em que há variação no vínculo montadoras-fornecedores

Fonte: autores

REAd I Porto Alegre - Edição 73 - N 3 - set/dez 2012 - p. 581-606 


\section{Análise dos resultados}

\subsection{Características gerais das empresas pesquisadas}

A Tabela 1 apresenta os dados compilados, referentes às principais características das empresas analisadas no estudo.

Tabela 1 - Características gerais das empresas

\begin{tabular}{lc}
\hline Média do número de empregados por planta & 602,1 \\
Média do faturamento anual (em R\$ milhões) & 227,1 \\
Percentual de compras em relação ao faturamento & $57,6 \%$ \\
Número de fornecedores que significam 80\% das aquisições & 2,7 \\
Número de fornecedores ativos por material & 3 \\
\hline
\end{tabular}

Fonte: Dados da pesquisa

A primeira camada de fornecedores da indústria automobilística possui um grau de terceirização de 57,6\%, medido pelo percentual que as aquisições representam em relação ao faturamento anual da empresa. Este dado é equivalente ao grau de terceirização médio das montadoras de automóveis em todo o mundo - $60 \%$ do faturamento, em média, segundo Monczka et al. (2009).

Esta informação sugere que os fornecedores de primeira camada possuem um razoável grau de dependência em relação aos fornecedores de segunda camada. Tal fato, combinado com as exigências crescentes por parte das montadoras por desempenho superior dos fornecedores de primeira camada, reforça a demanda por uma estratégia de suprimento apoiada no desenvolvimento e manutenção de um alto grau de interação com os seus fornecedores estratégicos.

Para Lysons e Farrington (2006), desenvolver um alto grau de interação com fornecedores estratégicos envolve a manutenção de um reduzido número de contatos com a segunda camada. As empresas da primeira camada apontam que concentram o volume de aquisições em um número reduzido de fornecedores de segunda camada - em média 2,7 fornecedores representam $80 \%$ do valor financeiro adquirido anualmente.

\subsection{Comparativo entre cadeias de suprimento das montadoras europeias e norte- americanas}

A Tabela 2 apresenta as informações sobre a importância atribuída aos critérios de desempenho e o valor calculado para o alinhamento, considerando a segmentação entre montadoras de origem europeia ou norte-americana. No primeiro grupo, foram citadas as REAd I Porto Alegre - Edição 73 - Nº 3 - set/dez 2012 - p. 581-606 
Alinhamento estratégico nas cadeias de suprimento da indústria automobilística brasileira montadoras Fiat, Volkswagen, Renault, Peugeot/Citroen e Mercedes-Benz. No segundo grupo, foram citadas as montadoras General Motors e Ford. Nas linhas, são apresentados os critérios de desempenho mais relevantes para o setor. Para cada um dos grupos, são apresentadas três colunas: importância do critério de desempenho para a estratégia de suprimento do fornecedor de primeira camada; importância que a montadora atribui ao critério de desempenho nas relações com a primeira camada; e o alinhamento, ou seja, a diferença em valor absoluto entre a primeira coluna e a segunda coluna.

Tabela 2 - Importância dos critérios de desempenho segundo percepção dos fornecedores de primeira camada, segmentados pela origem das montadoras clientes

\begin{tabular}{|c|c|c|c|c|c|c|}
\hline \multirow{2}{*}{$\begin{array}{c}\text { Criterio de } \\
\text { desempenho }\end{array}$} & \multicolumn{3}{|c|}{ Montadoras Europeias } & \multicolumn{3}{|c|}{ Montadoras Norte-Americanas } \\
\hline & $\begin{array}{c}\text { Fornecedor } \\
1^{\mathrm{a}} \text { camada }\end{array}$ & Montadora & $\begin{array}{l}\text { Alinha- } \\
\text { mento }\end{array}$ & $\begin{array}{c}\text { Fornecedor } \\
\mathbf{1}^{\mathrm{a}} \text { camada }\end{array}$ & Montadora & $\begin{array}{l}\text { Alinha- } \\
\text { mento }\end{array}$ \\
\hline Qualidade certificada & 8,3 & 7,6 & 0,71 & 8,1 & 6,4 & 1,65 \\
\hline Pontualidade & 7,8 & 7,0 & 0,71 & 8,2 & 7,0 & 1,20 \\
\hline Rapidez tempo de ciclo & 7,2 & 7,0 & 0,21 & 6,9 & 6,3 & 0,65 \\
\hline Menor preço & 6,4 & 6,1 & 0,32 & 5,6 & 5,7 & 0,10 \\
\hline Capacidade de produção & 5,4 & 6,1 & 0,71 & 5,8 & 6,7 & 0,95 \\
\hline Situação financeira & 5,1 & 5,5 & 0,36 & 4,0 & 5,5 & 1,55 \\
\hline Suporte a DNP & 4,6 & 4,6 & 0,07 & 6,1 & 5,4 & 0,65 \\
\hline Flexibilidade & 4,3 & 4,5 & 0,14 & 4,5 & 4,0 & 0,55 \\
\hline $\begin{array}{l}\text { Abertura de planilha de } \\
\text { custos }\end{array}$ & 3,3 & 3,9 & 0,68 & 3,6 & 5,4 & 1,85 \\
\hline $\begin{array}{l}\text { Plano de produção } \\
\text { compartilhado }\end{array}$ & 2,8 & 2,6 & 0,14 & 3,0 & 2,8 & 0,15 \\
\hline \multicolumn{3}{|c|}{ Soma do alinhamento } & 4,07 & \multicolumn{2}{|c|}{ Soma do alinhamento } & 9,30 \\
\hline
\end{tabular}

Fonte: Dados da pesquisa

Pode-se concluir, a partir das informações apresentadas na Tabela 2, que os fornecedores de primeira camada das montadoras europeias possuem estratégias de suprimento mais alinhadas com a estratégia de suprimento adotada pelas montadoras, uma vez que o valor obtido na soma do alinhamento - 4,07 - é significativamente menor do que o valor obtido na soma do alinhamento para o grupo formado pelos fornecedores de primeira camada das montadoras norte-americanas $-9,30$.

Cadeias de suprimentos com estratégias não-alinhadas entre os elos sofrem reflexos negativos em seu desempenho, uma vez que a ausência de uma estratégia única de atuação impede o alcance de objetivos e metas comuns ao longo da estrutura de relacionamentos (CHOPRA E MEINDL, 2011).

Os fornecedores de primeira camada das montadoras europeias adotam um comportamento similar ao dessas montadoras, definindo uma hierarquia clara na importância dos critérios de desempenho. Para essas empresas, qualidade certificada, pontualidade e rapidez no tempo de ciclo se destacam como sendo o conjunto de critérios mais importante. A seguir, surgem os 


\section{Ricardo S. Martins, Osmar V. Souza Filho \& Susana Carla Farias Pereira}

critérios preço, capacidade de produção e situação financeira. Para esse grupo de empresas, os critérios menos relevantes dentre os dez analisados são: suporte a DNP, flexibilidade, abertura de planilha de custos e compartilhamento de planos de produção.

De maneira similar, os fornecedores de primeira camada das montadoras norte-americanas adotam uma hierarquização dos critérios de desempenho muito parecida com a descrita no parágrafo anterior. Vale ressaltar que o critério suporte a DNP é mais valorizado por essas empresas do que pelas empresas do grupo anterior, em detrimento do critério situação financeira, que perde importância, nesse caso.

Porém, esses mesmos fornecedores de primeira camada percebem uma estratégia de suprimentos das montadoras norte-americanas distinta daquela por eles adotada, no que se refere à importância dos critérios de desempenho. As montadoras norte-americanas parecem não hierarquizar os critérios de desempenho em três grupos distintos, segundo a nota de importância dos mesmos, como o fazem as montadoras européias, Oito dos dez critérios de desempenho apresentaram nota de importância em uma faixa muito estreita, que variou de 5,4 a 7,0. Apenas dois critérios se destacaram dos demais: flexibilidade e compartilhamento de planos de produção, com notas 4,0 e 2,8, respectivamente.

Essa constatação explica o fato do maior alinhamento das montadoras europeias e seus fornecedores de primeira camada em suas estratégias de suprimento do que montadoras norteamericanas e seus fornecedores de primeira camada.

Fornecedores de primeira camada das montadoras norte-americanas preferem replicar à montante uma estratégia mais próxima daquela adotada pelas montadoras europeias, pelo menos no que se refere à análise dos critérios utilizados para avaliação dos mesmos. Considerando que todos os fornecedores de primeira camada amostrados que são fornecedores das montadoras norte-americanas também o são das montadoras europeias, pode-se considerar a ocorrência de duas possibilidades:

a) As montadoras europeias são mais eficazes em comunicar seus objetivos e estratégias com seus fornecedores de primeira camada, obtendo com isso cadeias de suprimento mais alinhadas nas estratégias de suprimento, em detrimento das montadoras norte-americanas, que teriam dificuldades maiores em obter $\mathrm{o}$ alinhamento;

REAd I Porto Alegre - Edição 73 - N 3 - set/dez 2012 - p. 581-606 
Alinhamento estratégico nas cadeias de suprimento da indústria automobilística brasileira

b) As montadoras norte-americanas adotam estratégias de suprimento mais sofisticadas nos seus relacionamentos à montante, quando comparadas com aquelas adotadas pelas montadoras europeias, sem que os fornecedores de primeira camada as tenham acompanhado nesse movimento.

A análise da importância atribuída pelas montadoras e seus fornecedores de primeira camada aos dez critérios de desempenho parece confirmar a segunda possibilidade. Montadoras norte-americanas, segundo a percepção dos próprios fornecedores de primeira camada, valorizam, mais do que as montadoras europeias, critérios de desempenho que favorecem práticas colaborativas, como suporte ao DNP e abertura de planilha de custos.

A Figura 4 apresenta, de maneira esquemática, as principais conclusões desse comparativo.

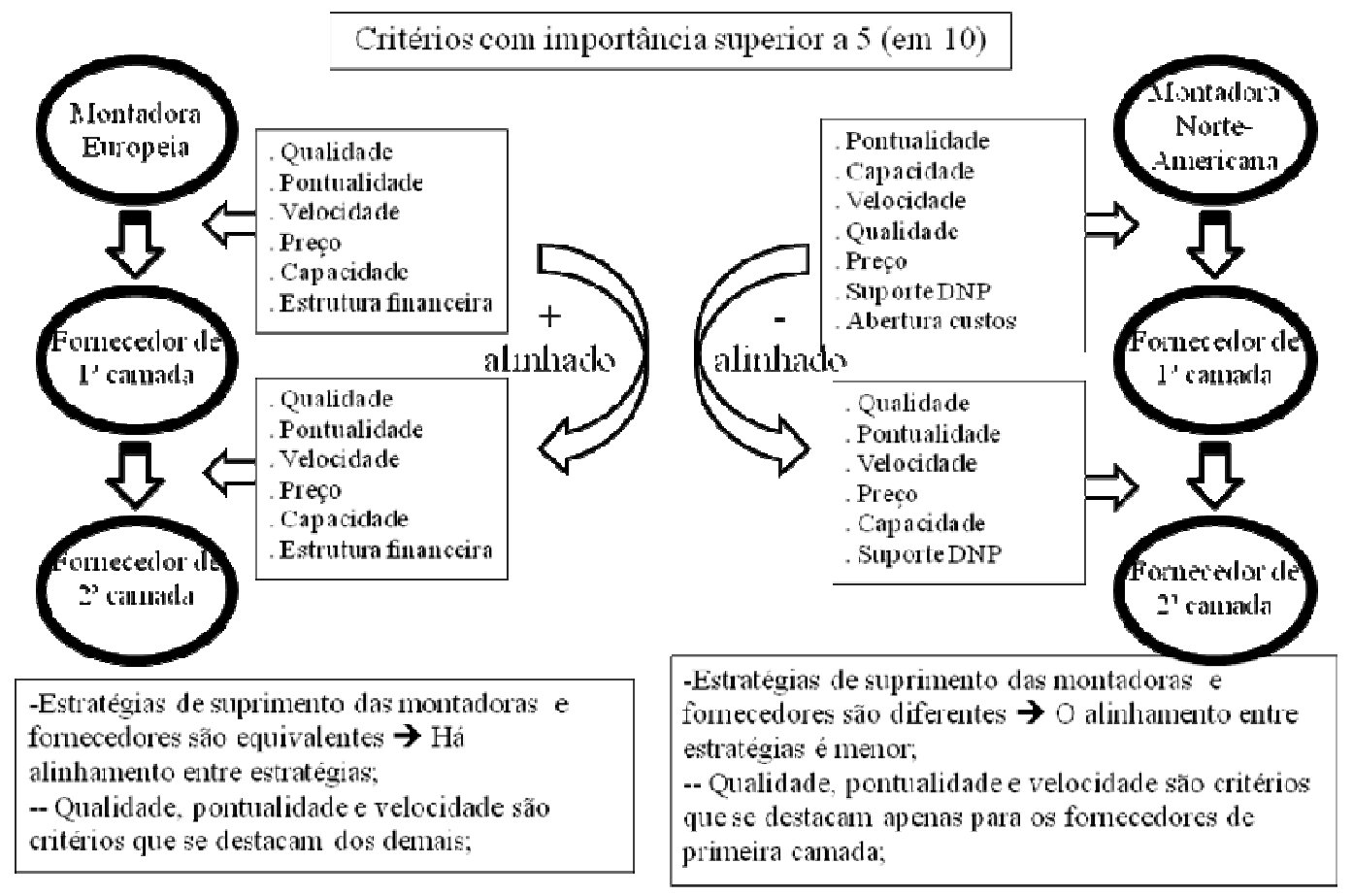

Figura 4 - Comparativo do alinhamento estratégico entre cadeias de suprimento das montadoras europeias e montadoras norte-americanas

Fonte: autores

\subsection{Comparativo quando há variação no vínculo estabelecido entre o fornecedor de primeira camada e a montadora}

Para possibilitar esse comparativo, as respostas foram segmentadas em dois grupos distintos. O primeiro grupo é formado pelos fornecedores de primeira camada cuja principal montadora atendida representa pelo menos $50 \%$ de seu faturamento anual. O segundo grupo é 


\section{Ricardo S. Martins, Osmar V. Souza Filho \& Susana Carla Farias Pereira}

formado por todos os demais fornecedores de primeira camada amostrados, ou seja, empresas cujo faturamento se dispersa por diferentes montadoras.

Há diferentes razões pelas quais fornecedores de primeira camada e montadoras intensificam os seus vínculos - em alguns casos, chegando à dedicação total do fornecedor à montadora. Uma delas pode ser uma decisão de suprimentos da montadora baseada em estratégia de single sourcing, geralmente com interesse em consolidar volumes e assegurar a coordenação entre as atividades desempenhadas. Outra razão é a implantação de cinturões de fornecedores, quando os fornecedores de primeira camada são convidados pela montadora a transferir sua planta, ou constituir uma filial, em uma localização física próxima à planta da montadora - às vezes, anexa a ela. O objetivo, nestes dois casos, é criar as condições para que ocorra uma integração avançada entre as atividades das duas empresas, especialmente processos operacionais e de logística.

A Tabela 3 apresenta as informações sobre a importância atribuída aos critérios de desempenho e o valor calculado para o alinhamento, considerando a segmentação entre dois grupos distintos: fornecedores de primeira camada fortemente vinculados a uma montadora e fornecedores de primeira camada cujo vínculo é disperso entre diferentes montadoras. Nas linhas, são apresentados os critérios de desempenho mais relevantes para o setor. Para cada um dos grupos, são apresentadas três colunas: importância do critério de desempenho para a estratégia de suprimento do fornecedor de primeira camada; percepção quanto à importância dada pela montadora ao critério de desempenho nas relações com a primeira camada; e o alinhamento, ou seja, a diferença em valor absoluto entre a primeira coluna e a segunda coluna.

Tabela 3 - Importância dos critérios de desempenho segundo percepção da primeira camada, segmentados pela intensidade do vínculo montadoras -fornecedor

\begin{tabular}{l|c|c|c|c|c|c}
\hline \multirow{2}{*}{ Critérios de desempenho } & \multicolumn{3}{|c}{ Forte vínculo } & \multicolumn{3}{c}{ Vínculo disperso } \\
\cline { 2 - 7 } & $\begin{array}{c}\text { Fornecedor } \\
\mathbf{1}^{\mathbf{a}} \text { camada }\end{array}$ & Montadora & $\begin{array}{c}\text { Alinha } \\
\text { mento }\end{array}$ & $\begin{array}{c}\text { Fornecedor } \\
\mathbf{1}^{\mathbf{a}} \text { camada }\end{array}$ & Montadora & $\begin{array}{c}\text { Alinha } \\
\text { mento }\end{array}$ \\
\hline Qualidade certificada & 8,8 & 9,1 & 0,2 & 8,1 & 6,2 & 1,9 \\
\hline Pontualidade & 7,4 & 7,0 & 0,4 & 7,9 & 7,6 & 0,3 \\
\hline Rapidez tempo de ciclo & 7,4 & 7,5 & 0,1 & 6,9 & 6,6 & 0,3 \\
\hline Menor preço & 7,5 & 6,7 & 0,8 & 5,0 & 5,2 & 0,2 \\
\hline Capacidade de produção & 5,5 & 6,7 & 1,2 & 5,7 & 6,1 & 0,3 \\
\hline Situação financeira & 6,1 & 4,8 & 1,3 & 4,2 & 5,7 & 1,5 \\
\hline Suporte a DNP & 2,8 & 2,8 & 0,0 & 6,6 & 6,2 & 0,4 \\
\hline Flexibilidade & 3,8 & 4,9 & 1,1 & 4,7 & 4,2 & 0,5 \\
\hline $\begin{array}{l}\text { Abertura de planilha de } \\
\text { custos }\end{array}$ & 3,0 & 3,1 & 0,1 & 3,3 & 4,8 & 1,5 \\
\hline
\end{tabular}

REAd I Porto Alegre - Edição 73 - Nº 3 - set/dez 2012 - p. 581-606 
Alinhamento estratégico nas cadeias de suprimento da indústria automobilística brasileira

\begin{tabular}{l|c|c|c|c|c|c}
\hline $\begin{array}{l}\text { Plano de produção } \\
\text { compartilhado }\end{array}$ & 2,7 & 2,5 & 0,2 & 2,9 & 2,5 & 0,5 \\
\hline \multicolumn{5}{r|}{ Soma do alinhamento } \\
\multicolumn{6}{c}{ Fonte: Resultados da pesquisa }
\end{tabular}

Fonte: Resultados da pesquisa

A análise das informações apresentadas na Tabela 3 permite concluir que a estratégia de suprimento das montadoras e de seus fornecedores de primeira camada está mais alinhada quando há forte vínculo entre essas empresas, ou seja, quando uma determinada montadora representa $50 \%$ ou mais do faturamento do fornecedor de primeira camada. O indicador que suporta esta afirmação é o menor valor para a soma do alinhamento no primeiro grupo em relação ao valor para o segundo grupo.

Tal conclusão confirma a expectativa prévia de que a existência de um forte vínculo entre fornecedores de primeira camada e montadora permite aprofundar o grau de integração entre as empresas, aumentando o nível de serviço e reduzindo o risco do suprimento. Como consequência, a governança da montadora tem maior poder de influência na estratégia de suprimentos do fornecedor de primeira camada, alinhando as estratégias em busca de algo próximo a uma estratégia única de atuação.

Por outro lado, quando as montadoras de automóveis não são exclusivas ou predominantes na relação com um determinado fornecedor de primeira camada, é esperada uma menor influência daquelas nas decisões de suprimento destes, o que se refletiu em um menor alinhamento entre as estratégias de suprimentos, nesses casos.

O critério de desempenho qualidade é o principal para quase todas as situações, exceção feita às montadoras cujos fornecedores de primeira camada não são fortemente vinculados a elas. Para estas, o critério de desempenho mais importante é a pontualidade, o que pode ser atribuído a um menor nível de integração dos processos entre montadoras e fornecedores de primeira camada, decorrente do menor vínculo estabelecido entre as empresas. Tal situação aumenta o risco do suprimento, uma vez que interfere no grau de certeza quanto à posse de recursos externos no momento adequado.

As montadoras do segundo grupo, cujos fornecedores de primeira camada não são intensamente vinculados a elas, parecem adotar uma estratégia de suprimentos mais colaborativa quanto à determinação do preço a ser pago pelos materiais. Porém, não são seguidas por seus fornecedores neste aspecto, já que estes adotam comportamento similar aos fornecedores de primeira camada e respectivas montadoras do primeiro grupo, que é aquele formado por empresas fortemente vinculadas entre si. Tal conclusão é possível a partir da 


\section{Ricardo S. Martins, Osmar V. Souza Filho \& Susana Carla Farias Pereira}

análise da importância atribuída aos critérios de desempenho preço e abertura de planilha de custos.

A determinação de colaborar se manifesta novamente de maneira clara no segundo grupo de montadoras quando se analisa o critério suporte ao desenvolvimento de novos produtos atribuem importância média de 6,2, contra apenas 2,8 nas montadoras do primeiro grupo. Neste critério, em ambos os grupos, houve alinhamento entre as estratégias adotadas por fornecedores de primeira camada e pelas montadoras. $\mathrm{O}$ envolvimento de empresas fornecedoras e clientes em projetos de novos produtos é um indicador de colaboração, pois alavanca os relacionamentos entre as partes e reforça as parcerias, com perspectivas de médio a longo prazo (MONCZKA et al., 2009; LYSONS e FARRINGTON,2006).

A partir das informações apresentadas, é possível afirmar que a ocorrência do maior grau de alinhamento verificado entre montadoras e fornecedores de primeira camada fortemente vinculados não pressupõe colaboração entre as empresas. Pelo contrário, apresentaram comportamento mais colaborativo as montadoras cujas estratégias não se alinham com as adotadas pelos fornecedores diretos, uma vez que o vinculo entre eles é disperso.

Tal como ocorreu na primeira segmentação realizada, descrita no tópico 4.2, as informações apresentadas nesta seção oferecem evidências de que a adoção de práticas colaborativas por parte das montadoras provoca redução no alinhamento de estratégias de suprimento entre montadoras e fornecedores de primeira camada, uma vez que seus fornecedores não adotam o mesmo comportamento colaborativo a montante.

A existência de um forte vínculo entre as empresas na primeira camada, decorrentes de ações de integração ocorridas entre montadoras e seus fornecedores de primeira camada, não foi capaz de auxiliar na disseminação de práticas colaborativas nas cadeias de suprimento analisadas.

Já o menor alinhamento estratégico verificado no segundo grupo indica que os fornecedores de primeira camada ainda não são capazes de replicar as estratégias colaborativas na mesma intensidade com que as percebe nas relações com os clientes. Ou seja, a colaboração ainda não avançou claramente da primeira para a segunda camada.

A Figura 5 apresenta, de maneira esquemática, as principais conclusões desse comparativo.

REAd I Porto Alegre - Edição 73 - N 3 - set/dez 2012 - p. 581-606 
Alinhamento estratégico nas cadeias de suprimento da indústria automobilística brasileira

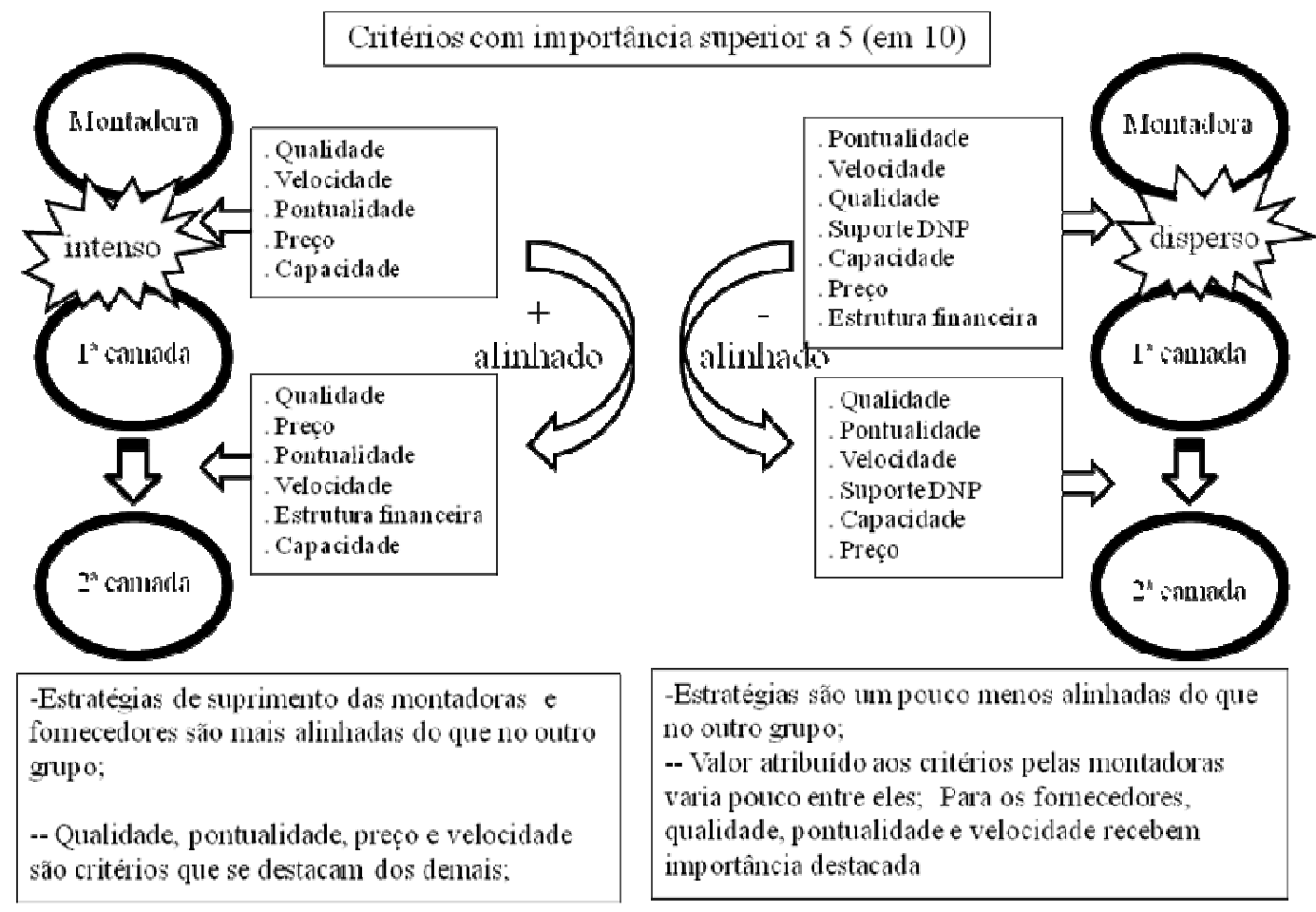

Figura 5 - Comparativo do alinhamento estratégico entre situações de vinculo intenso e de vínculo disperso entre montadoras e fornecedores de primeira camada

Fonte: autores

\subsection{Evidências dos relacionamentos na cadeia automobilística brasileira à luz da Network Theory}

A Network Theory preconiza que as empresas devem combinar a sua estrutura interna de recursos com a estrutura de recursos possuída pelos fornecedores como única maneira de se tornarem mais eficientes e responsivas às demandas dos clientes (GADDE E JONSSON, 2007; FORD et al., 2008).

A estratégia de suprimentos adotada deve exercer um papel destacado nesse aspecto, pois é por meio dos projetos colaborativos com fornecedores, da coordenação na execução das atividades e do estabelecimento de vínculos aprofundados com os demais atores que uma empresa se habilita a prover um fluxo ininterrupto de recursos necessários para o seu bom desempenho (GADDE E HAKANSSON, 2001; GADDE E JONSSON, 2007).

A motivação que deve predominar é o aprimoramento do desempenho de ambas e da rede como um todo, a partir do entendimento que a coordenação entre as atividades é um fator de produtividade (FORD et al., 2008). A forma de integração entre as atividades internas e aquelas desempenhadas pelos fornecedores afeta o desempenho de ambas e de toda a rede. Tais conexões representam uma forma de coordenação que gerará a otimização na exploração dos recursos disponíveis. Como a efetividade de uma estratégia de suprimentos está 


\section{Ricardo S. Martins, Osmar V. Souza Filho \& Susana Carla Farias Pereira}

diretamente associada à gestão da base de fornecedores, com o intuito de obter recursos externos que apoiem a busca por consistência entre as capacidades internas e a vantagem competitiva procurada pela empresa (LYSONS E FARRINGTON, 2006), faz-se necessário que essa estratégia permita que haja coordenação da execução das atividades internas e externas.

O estudo oferece evidências de que a existência de um maior alinhamento nas estratégias de suprimentos entre determinados grupos de montadoras e seus fornecedores de primeira camada não produziu um aumento no nível de coordenação entre as atividades desempenhadas, já que as relações não são baseadas em ações colaborativas entre as empresas. Este é o caso das montadoras de origem europeia, no primeiro comparativo, e que possuem fornecedores fortemente vinculados, no segundo comparativo.

A estratégia de suprimentos de uma empresa tem o importante papel de criar vantagens competitivas a partir do fortalecimento dos vínculos entre as empresas envolvidas na rede de suprimentos. Este é o objetivo das práticas de remodelação das estratégias de suprimento na indústria automobilística mundial, que adotou modelos colaborativos de gestão das relações com um número reduzido de fornecedores estratégicos (BRONZO et al., 2005).

Portanto, à luz da Network Theory, é possível afirmar, a partir deste estudo, que as montadoras cujos requisitos são a adoção de práticas mais colaborativas com a primeira camada não conseguiram que seus fornecedores replicassem tais práticas nas relações com a segunda camada. Dessa forma, oportunidades de estender práticas colaborativas aos demais elos das cadeias de suprimento são desperdiçadas, impedindo que o alinhamento de estratégias seja verificado também em um ambiente de colaboração.

Ainda, são pouco evidentes os sinais de que os fornecedores de primeira camada adotem estratégias de suprimentos que reforcem o vínculo com os fornecedores de segunda camada, já que não adotam ações colaborativas com os mesmos.

Como resultado desta ausência de vínculos aprofundados entre os atores, tais cadeias de suprimento têm sua capacidade de inovação e de aumento da produtividade afetadas negativamente (GADDE E HAKANSSON, 2001; FORD et al., 2003; GADDE E JONSSON, 2007; FORD et al., 2008). Relacionamentos não apenas complementam as competências internas de uma empresa, segundo a Network Theory; eles, efetivamente, interferem no desenvolvimento dessas competências, o que influenciará diretamente o desempenho das 
Alinhamento estratégico nas cadeias de suprimento da indústria automobilística brasileira demais empresas envolvidas, tornando o resultado final da rede de relacionamentos um produto ou serviço mais ou menos competitivo, a depender da forma como essas interações serão gerenciadas.

\section{Considerações finais}

Este estudo teve por objetivo avaliar evidências de alinhamento das estratégias de suprimento nas cadeias de suprimentos da indústria automobilística brasileira.

Verificou-se que a existência de um alto grau de dependência de um fornecedor em relação a uma montadora específica, decorrentes de ações de integração de processos com esses fornecedores de primeira camada, reforça o alinhamento estratégico na cadeia de suprimentos.

Verificou-se, ainda, que as montadoras europeias instaladas no Brasil - Fiat, Volkswagen, Renault e Mercedes-Benz - e seus respectivos fornecedores de primeira camada adotam estratégias de suprimentos mais alinhadas entre si, quando comparadas com as montadoras norte-americanas - General Motors e Ford.

No entanto, a análise detalhada dos critérios de seleção e avaliação do desempenho dos fornecedores, nas duas segmentações realizadas no estudo, demonstrou que esse maior grau de alinhamento estratégico não é acompanhado da adoção de práticas mais colaborativas entre as empresas.

Pelo contrário, nas situações em que o alinhamento estratégico é menor, os fornecedores de primeira camada atribuem às montadoras um padrão de comportamento que privilegia aspectos mais colaborativos na análise do desempenho dos fornecedores de primeira camada. As montadoras que se enquadram nesse padrão de comportamento são as norte-americanas General Motors e Ford, na primeira segmentação, e aquelas cujos fornecedores dispersam seu faturamento entre dois ou mais clientes estratégicos, na segunda segmentação.

Dadas as características da operação da indústria automobilística brasileira, em que os vínculos entre montadoras e fornecedores de primeira camada estão sendo reforçados - vide a criação de condomínios industriais e de cinturões de fornecedores - em busca de maior coordenação na execução de atividades e melhor acesso a recursos externos, a colaboração entre as empresas é requisito essencial para a geração de inovação, aumento da produtividade e reforço da capacidade competitiva.

O estudo permite concluir que os relacionamentos entre a primeira camada e a segunda camada de fornecedores na cadeia automobilística brasileira não são influenciados pelas estratégias das montadoras. Estas últimas, que, segundo a percepção da primeira camada, 


\section{Ricardo S. Martins, Osmar V. Souza Filho \& Susana Carla Farias Pereira}

valorizam em maior grau a critérios de desempenho colaborativos como compartilhamento de informações sobre planos de produção, abertura de planilha de custos e desenvolvimento conjunto de novos produtos, não influenciam a estratégia de suprimento adotada por estes fornecedores de primeira camada.

Assim, conclui-se que predominam as práticas de gestão de fornecedores que não estão alinhadas aos preceitos da Network Theory nas relações entre as empresas da indústria automobilística brasileira. Os fornecedores de primeira camada não atuam para fortalecer os vínculos com os fornecedores de segunda camada, em busca de aumento na coordenação das atividades. Sendo assim, oportunidades de aprimoramento do desempenho de ambas as empresas são desperdiçadas. As ineficiências resultantes desse baixo grau de coordenação afetarão a condição competitiva dos atores, individualmente, e da rede, como um todo.

As montadoras, por sua vez, quando adotam critérios de desempenho que privilegiam a colaboração, aproximando-se dos preceitos da Network Theory, não influenciam seus fornecedores de primeira camada em suas próprias estratégias de suprimento. Consequentemente, perde-se parte dos benefícios que a colaboração estendida a mais de uma camada de empresas seria capaz de produzir na cadeia de suprimentos.

Sumarizando-se as principais conclusões do estudo, há evidências de que a ocorrência de um maior alinhamento estratégico nas cadeias de suprimento analisadas se dá em situações de pouca ênfase em aspectos colaborativos. Desta forma, é válido questionar a busca por maior alinhamento de estratégias nas situações em que as práticas não estão em sintonia com os preceitos da Network Theory. Alinhar as práticas pelo viés não-colaborativo pode ser considerado um retrocesso nas experiências adotadas pelas cadeias da indústria automobilística, uma vez que o aumento na coordenação das atividades possibilitou a adoção de arranjos de suprimento enxuto e de desenvolvimento conjunto de inovações, cujos benefícios foram expostos ao longo do referencial teórico aqui apresentado.

São importantes as contribuições deste estudo no sentido do aprofundamento da compreensão do papel das estratégias de gestão do relacionamento no sucesso de cadeias de negócios. Tomando-se o caso da relação dos fornecedores da cadeia automobilística brasileira, objetivou-se entender como diferentes estratégias de gestão dos relacionamentos dão suporte e são suportadas pelo alinhamento definido para a cadeia. Está aberto aos pesquisadores envolvidos e à comunidade acadêmica em geral, contudo, um campo temático 
Alinhamento estratégico nas cadeias de suprimento da indústria automobilística brasileira de pesquisa que aborde a performance empresarial vinculada às estratégias de suprimento e de formação de parcerias entre empresas nas cadeias de suprimento. As evidências procuradas estão ao nível de diversas curiosidades científicas, sendo as principais delas: O nível de performance está relacionado às práticas colaborativas? Quanto mais alinhadas as práticas, melhor a performance? Estas são perguntas cujas respostas demandam novos estudos, abrangendo aspectos específicos da relação colaboração e desempenho nas cadeias de suprimento.

\section{Agradecimentos}

Este estudo teve o apoio financeiro da Fundação de Amparo à Pesquisa do Estado de Minas Gerais (Fapemig) e do Conselho Nacional de Desenvolvimento Científico e Tecnológico (CNPq). Os autores agradecem a estas instituições pelo apoio.

\section{REFERÊNCIAS}

BRONZO, M.; ARRUDA, R.; TAKAHASHI, B.; EDER, L. M. Organização da função logística dos grandes contratantes da cadeia de suprimentos da Fiat Automóveis do Brasil. In: XXIX Encontro da ANPAD. Brasília, 2005.

CARVALHO, E. Globalização e Estratégias Competitivas na Indústria Automobilística: uma abordagem a partir das principais montadoras instaladas no Brasil. Gestão \& Produção. V.12, n.1, p.121-133, 2005.

CHOI, T. Y.; WU, Z. Triads in Supply Networks: Theorizing Buyer-Supplier-Supplier Relationships. Journal of Supply Chain Management. 2009, v. 45, n. 1, pp. 8-25.

CHOPRA, S.; MEINDL, P. Gestão da Cadeia de Suprimentos: Estratégia, Planejamento e Operações. $4^{\mathrm{a}}$ edição. São Paulo: Pearson, 2011.

CHRISTOPHER, M. Logística e Gerenciamento da Cadeia de Suprimentos. $2^{\mathrm{a}}$ edição. São Paulo: Cengage, 2007.

DYER, J. Effective interfirm collaboration: how firms minimize transaction costs and maximize transaction value. Strategic Management Journal, 1997, v. 18, pp. 535-556.

DYER, J.; CHO, D.S., CHU, W. Strategic supplier segmentation: the next best practice in supply chain management. California Management Review, 1998, v.40, n. 2, pp. 57-77. 
DYER, J.; CHU, W. The Determinants of Trust in Supplier-automaker Relationships in the US, Japan and Korea. Journal of International Business Studies, 2000, v.31, n. 2, pp. 259285.

FORD, D.; et al.. Managing Business Relationships. Chichester: John Wiley \& Sons Ltd., 2003.

FORD, D.; GADDE, L.; SNEHOTA, I.; HAKANSSON, H.; WALUSZEWISKI, A. Analysing Business Interaction. In: 24th IMP conference. Uppsala: Sweden, 2008

GADDE, L.; HÅKANSSON, H. Supply network strategies. Chichester: John Wiley \& Sons, 2001.

GADDE, L.; JONSSON, P. Outsourcing and Supply Network Performance - consequences of sourcing and producing in low-cost countries. In: 23th IMP conference. Manchester: UK, 2007.

HALLDORSSON, A.; KORZAB, H.; MIKKOLA, J.; SKJOETT-LARSEN, T. Complementary Theories to Supply Chain Management. Supply Chain Management: An International Journal, 2007, v.12, n. 4, pp. 284-296.

HINES, P. Network Sourcing: a Hybrid Approach. International Journal of Purchasing and Materials Management, 1995, v. 31, n. 2, pp.17-24.

LEE, H. L. The Triple-A Supply Chain. Harvard Business Review, 2004, v. 82, n. 10, pp. 212.

LIKER, J. K.; CHOI, T. Y. Building Deep Supplier Relationships. Harvard Business Review, 2004, v. 82, n. 12, pp. 104-113.

LIMA, José Carlos de Souza. Um estudo sobre a reconfiguração da função compras em empresas do setor automotivo. São Paulo, 2004. Tese (Doutorado em Administração). Universidade de São Paulo.

LYSONS, K.; FARRINGTON, B. Purchasing and Supply Chain Management. Edinburg: Pearson, 2006. 
Alinhamento estratégico nas cadeias de suprimento da indústria automobilística brasileira

MONCZKA, R.; TRENT, R.; HANDFIELD, R. Purchasing and Supply Chain Management. $4^{\text {th }}$ edition. Mason: Cengage, 2009.

NARAYANAN, V. G.; RAMAN, A. Aligning Incentives in Supply Chains. Harvard Business Review, 2004, v. 82, n. 11, pp. 94-102.

OGDEN, J. A. Supply Base Reduction: an Empirical Study on Critical Success Factors. Journal of Supply Chain Management, 2006, v. 42, n. 4

PFOHL, H. C.; GAREIS, K. Supplier Parks in the German Automotive Industry. International Journal of Physical Distribution \& Logistics Management. 2005, v. 35, n. 5, pp 302-317.

VACHON, S.; HALLEY, A.; BEAUlIEU, M. Aligning Competitive Priorities in the Supply Chain: the Role of Interactions with Suppliers. International Journal of Operations \& Production Management. 2009, v. 29, n. 4, pp. 322-340.

VAN der VAART, T.; VAN DONK, D. P. Buyer-focused Operations as a Supply Chain Strategy. International Journal of Operations \& Production Management. 2006, v. 26, n. 1, pp. 8-23.

WOMACK, J.P.; JONES, D.T.; ROOS, D. The Machine That Changed the World. Free Press: New York, 2007.

ZIRPOLI, F.; CAPUTO, M. The Nature of Buyer-Supplier Relationships in Co-design Activities: The Italian Auto Industry Case. International Journal of Operations \& Production Management. 2002, v. 22, n. 12, pp. 1389-1410. 